\title{
Pseudomonas aeruginosa mutations in lasl and rhll quorum sensing systems result in milder chronic lung infection
}

\author{
Hong Wu, ${ }^{1}$ Zhijun Song, ${ }^{1,4}$ Michael Givskov, ${ }^{2}$ Gerd Doring, ${ }^{3}$ \\ Dieter Worlitzsch, ${ }^{3}$ Kalai Mathee, ${ }^{4}$ Jørgen Rygaard ${ }^{5}$ and Niels Høiby ${ }^{1}$
}

Author for correspondence: Hong Wu. Tel: +45 35456427. Fax: +45 35456412.

e-mail: wuhong@get2net.dk

1 Department of Clinical Microbiology, 9301 Rigshospitalet, Juliane Maries Vej 22, DK-2100, Copenhagen $\varnothing$, Denmark

2 Institute of Microbiology, Technical University of Denmark, DK-2800, Lyngby, Denmark

3 Hygiene Institute, University of Tübingen, D-72074, Tübingen, Germany

4 Department of Biological Sciences, Florida International University, University Park, Miami, FL 33199, USA

5 Bartholin Institute, Kommunehospitalet, Copenhagen, Denmark

\begin{abstract}
To understand the importance of quorum sensing in chronic Pseudomonas aeruginosa lung infection, the in vivo pathogenic effects of the wild-type $P$. aeruginosa PAO1 and its double mutant, PAO1 lasl rhll, in which the signalgenerating parts of the quorum sensing systems are defective were compared. The rat model of $\boldsymbol{P}$. aeruginosa lung infection was used in the present study. The rats were killed on days 3, 7, 14 and 28 after infection with the $P$. aeruginosa strains. The results showed that during the early stages of infection, the PAO1 double mutant induced a stronger serum antibody response, higher production of pulmonary interferon $\gamma$, and more powerful blood polymorphonuclear leukocyte (PMN) chemiluminescence compared to its wild-type counterpart. On days 14 and 28 post-infection, significantly milder lung pathology, a reduction in the number of mast cells present in the lung foci, a reduced number of lung bacteria, and minor serum IgG and IgG1 responses but increased lung interferon $\gamma$ production were detected in the group infected with the PAO1 double mutant when compared with the PAO1infected group. Delayed immune responses were observed in the PAO1infected group and they might be associated with the production of virulence factors that are controlled by the quorum sensing systems. The conclusion of this study is that functional lasl and $r h l l$ genes of $P$. aeruginosa PAO1 play a significant role during lung infection.
\end{abstract}

Keywords: lasI and rhlI, $\mathrm{N}$-acylhomoserine lactones, chronic lung infection, cystic fibrosis, rat model

\section{INTRODUCTION}

Pseudomonas aeruginosa is an opportunistic pathogen; $P$. aeruginosa lung infection is commonly found in patients with cystic fibrosis (CF) and immunocompromised persons. The complications associated with $P$. aeruginosa pulmonary infection are the main cause of death in CF patients (Govan \& Deretic, 1996; Høiby, 1993). The reason for this is partly because of the fact that once chronic $P$. aeruginosa infection becomes established in the CF lung, it cannot be eradicated with antibiotic treatment mainly due to development of resistance to the host defence systems, and the pro-

Abbreviations: $\mathrm{AHL}, \mathrm{N}$-acylhomoserine lactone; $\mathrm{CF}$, cystic fibrosis; IFN- $\gamma$ interferon $\gamma_{i}$ IL, interleukin; LIMP, lung index of macroscopic pathology; $\mathrm{MN}$, mononuclear leukocyte; p.i., post-infection; PMN, polymorphonuclear leukocyte; St-Ag, $P$. aeruginosa standard antigen. duction of alginate and $\beta$-lactamase (Ciofu et al., 1994; May et al., 1991; Pedersen, 1992). It is therefore urgent to find a new approach to the treatment of chronic $P$. aeruginosa lung infection in $\mathrm{CF}$ patients (Finch et al., 1998; Hartman \& Wise, 1998).

$P$. aeruginosa can produce a number of cell-associated and extracellular virulence factors which contribute to its pathogenesis (Doring et al., 1984, 1985, 1987; Jaeger, 1994; Van Delden \& Iglewski, 1998). The extracellular virulence factors include proteases (elastase, Staphylolytic protease and alkaline protease), pigments (pyocyanin, pyoverdine), haemolysins, exoenzyme $S$ and exotoxin A (Pollack, 1984; Van Delden \& Iglewski, 1998). In P. aeruginosa, it has been demonstrated that the production of most of the extracellular virulence factors is controlled by quorum sensing systems in vitro (Pesci et al., 1997; Pesci \& Iglewski, 1997; Van Delden 
\& Iglewski, 1998). Quorum sensing systems exert their action by small diffusible signal molecules called $\mathrm{N}$ acylhomoserine lactones (AHLs) (Salmond et al., 1995; Fuqua et al., 1996; Fuqua \& Greenberg, 1998). The signal molecules are synthesized from precursors by a synthetase (a LuxI homologue) and they interact with a transcriptional activator (a LuxR homologue) to induce the expression of target genes (Fuqua et al., 1996). In $P$. aeruginosa there are at least two different quorum sensing systems: las and rbl (Gambello \& Iglewski, 1991; Seed et al., 1995; Ochsner \& Reiser, 1995), which code for synthetases (LasI/RhlI) and cognate transcriptional regulators (LasR/RhlR). The lasI-lasR system has been shown to modulate expression of lasI itself (Seed et al., 1995), lasB (elastase) (Passador et al., 1993; Pearson et al., 1997), las A (Staphylolytic protease) (Gambello et al., 1993), apr (alkaline protease) (Gambello et al., 1993), the xcp secretion pathway (Chapon-Herve et al., 1997), twitching motility (Glessner et al., 1999) and rhlR (Latifi et al., 1996; Pesci et al., 1997). The $r h l I-r h l R$ system modulates expression of rhll itself (Latifi et al., 1996), rhlAB (rhamnolipid biosynthesis) (Ochsner \& Reiser, 1995; Pearson et al., 1997), lasB (elastase) (Brint \& Ohman, 1995 ; Pearson et al., 1995, 1997), twitching motility (Glessner et al., 1999) and rpoS (Latifi et al., 1996). The lasI and rhlI products are $\mathrm{N}$-oxododecanoyl homoserine lactone (OdDHL, $3 \mathrm{OC}_{12}-\mathrm{HSL}$ or PAI-1) (Pearson et al., 1994) and Nbutyryl homoserine lactone (BHL, $\mathrm{C}_{4}$-HSL or PAI-2) (Pearson et al., 1995; Winson et al., 1995), respectively. Knowledge of how quorum sensing systems of $P$. aeruginosa operate during infection may help us to find a new approach to the treatment of chronic $P$. aeruginosa lung infections (Finch et al., 1998; Hartman $\&$ Wise, 1998). A few in vivo studies have demonstrated that the virulence of $P$. aeruginosa is associated with quorum sensing. For instance, the importance of a functional lasR gene has been shown in a neonatal mouse model of pneumonia (Tang et al., 1996). The virulence of lasI and rhlI mutants has been reported in a burned-mouse model (Rumbaugh et al., 1999), and we have previously demonstrated that the production of AHLs from $P$. aeruginosa can be directly detected in the lung tissues of mice with $P$. aeruginosa infection (Wu et al., 2000). OdDHL has been shown to induce an imbalance of the Th1/Th2 (T helper cells) response in vitro, i.e. suppressing interleukin (IL)-12 synthesis, enhancing antibody and IgG1 responses, and promoting IgE production from blood cells stimulated by IL-4 (Telford et al., 1998). All these data indicate that the quorum sensing systems of $P$. aeruginosa play an important role during the infectious process.

We wished to further elucidate the involvement of quorum sensing in chronic $P$. aeruginosa lung infection. In this study, we used a $P$. aeruginosa PAO1 lasI rhlI double mutant (Pearson et al., 1997) to infect rats intratracheally and compared the severity of the resulting lung infection with that caused by its wild-type counterpart PAO1. The bacteria were embedded in alginate beads and the resultant infection mimics the $P$. aeruginosa infection found in the CF lung (Pedersen et al., 1990). Immune parameters, lung bacteriology and lung pathology were evaluated at four different time points on days $3,7,14$ and 28 post-inoculation.

\section{METHODS}

Bacterial strains, culture media and experimental animals. The $P$. aeruginosa strains used were wild-type PAO1 and its double mutant, PAO1 lasI rhlI, which is also called PAO1-JP2 (PAO1 arbli:: Tn501 lasI:: Tc ${ }^{\mathrm{r}}, \mathrm{Hg}^{\mathrm{r}}$ ) (Brint \& Ohman, 1995; Pearson et al., 1997). Both PAO1 and its double mutant were grown in Luria-Bertani (LB) liquid medium or agar plates. Tetracycline $\left(100 \mu \mathrm{g} \mathrm{ml}^{-1}\right)$ and mercuric chloride $\left(50 \mu \mathrm{g} \mathrm{ml}^{-1}\right)$ (Sigma) were added to LB medium to maintain the mutations in PAO1 (lasI rhlI). A total of 170 female Lewis rats, each 7 weeks old with a body weight of about $150 \mathrm{~g}$ (Charles River) were used; details of animal numbers used in the study are shown in Table 1.

Immobilization of bacteria in seaweed alginate beads. Alginate is commonly produced by the mucoid P. aeruginosa, which is frequently found in the lungs of CF patients. The importance of alginate in the pathogenesis of $P$. aeruginosa has been demonstrated by the ability of intratracheally inoculated $P$. aeruginosa, embedded in minute seaweed alginate beads, to establish chronic $P$. aeruginosa lung infection. The two $P$. aeruginosa strains were each immobilized in seaweed alginate beads as described by Pedersen et al. (1990). First, $1 \mathrm{ml}$ bacteria cultured at $37^{\circ} \mathrm{C}$ for $18 \mathrm{~h}$ was mixed with $9 \mathrm{ml}$ sterile seaweed alginate (Protanal 10/60, Protan A/S). Next, the mixture was forced with air through a channel into a solution of $0 \cdot 1 \mathrm{M} \mathrm{CaCl}_{2}$ in $0 \cdot 1 \mathrm{M}$ Tris/ $\mathrm{HCl}$ buffer $(\mathrm{pH} 7 \cdot 0)$. The suspension of PAO1 or PAO1 lasI rhlI was then adjusted to $5 \times 10^{8}$ c.f.u. $\mathrm{ml}^{-1}$ and the yield was confirmed by colony counts.

Challenge procedures and blood sample collection. Before challenge, all rats were anaesthetized by subcutaneous injection of a 1:1 mixture of etomidate (Janssen) and midazolam (Roche) at a dose of $1.5 \mathrm{ml}(\mathrm{kg} \text { body weight })^{-1}$ and tracheotomized (Johansen et al., 1993). Intratracheal challenge with alginate beads was performed as described by Johansen et al. (1993). Each rat received $0 \cdot 1 \mathrm{ml}$ alginate beads containing $5 \times 10^{7}$ c.f.u. PAO1 or PAO1 lasI rhll. The incision was sutured with silk and healed without any complications. The animals were killed by using $20 \%(\mathrm{w} / \mathrm{v}$ ) pentobarbital (DAK) at a dosage of $2 \mathrm{ml}(\mathrm{kg} \text { body weight })^{-1}$ and blood samples were obtained by cardiac puncture.

Macroscopic pathology of the lungs. Eighteen to nineteen lungs from each time point in each group were macroscopically described in situ and after removal from the thoracic cavities. The macroscopic lung pathology was expressed as the lung index of macroscopic pathology (LIMP) as described by Song et al. (1998) according to the modified formula: LIMP $=$ lung area with pathological changes divided by the area of the whole lung. The macroscopic lung pathology included lung abscess, consolidation, atelectasis and haemorrhage.

Lung histopathology. Lung histopathology was carried out with eight lungs selected randomly from each group of rats at each time point. The following parameters were evaluated.

Size of lung abscesses. This was expressed as diameter ( $\mathrm{mm})$. Lung sections were made at the middle of a lung abscess to get its maximal diameter, which was measured with a micro-ruler under the microscope. 
Table 1. Number of animals used in each group for evaluation of different parameters on different days p.i.

The actual total number of animals used in the study was 74 rats in the PAO1 group and 75 rats in the lasI rhlI group since some rats died from infection.

\begin{tabular}{|ccccccc|}
\hline $\begin{array}{l}\text { Days } \\
\text { p.i. }\end{array}$ & Group & $\begin{array}{c}\text { Gross } \\
\text { pathology }\end{array}$ & $\begin{array}{c}\text { Bacteriology } \\
\text { and cytokines }\end{array}$ & Histopathology & $\begin{array}{c}\text { Chemiluminescence } \\
\text { Antibody } \\
\text { response }\end{array}$ \\
\hline \multirow{2}{*}{3} & PAO1 & 19 & 11 & 8 & 9 & 15 \\
& lasI rhlI & 19 & 11 & 8 & 12 & 15 \\
7 & PAO1 & 19 & 11 & 8 & 11 & 15 \\
& lasI rhlI & 19 & 11 & 8 & 12 & 15 \\
14 & PAO1 & 18 & 10 & 8 & 11 & 15 \\
& lasI rhlI & 19 & 11 & 8 & 12 & 15 \\
& PAO1 & 18 & 10 & 8 & - & 15 \\
\hline
\end{tabular}

Classification of acute or chronic inflammation. This was assigned by a scoring system based on the proportion of polymorphonuclear leukocytes (PMNs) and mononuclear leukocytes (MNs) in the inflammatory foci. Acute inflammation was defined as an inflammatory infiltration dominated by PMNs (PMNs 90\%, MNs $<10 \%$ ), whereas chronic inflammation was defined as a predominance of MNs (MNs $>90 \%$, PMNs $<10 \%$ ), which included lymphocytes, plasma cells and the presence of granulomas (Johansen et al., 1994).

Mast cell count. Toluidine blue staining was performed to detect mast cells in the lung tissues (Kiernan, 1981). Ten representative fields (viewed at $500 \times$ magnification) were selected along the inflammatory foci to count the number of mast cell as described previously (Song et al., 1997).

Preparation of PMNs. PMNs were isolated from 9 to 12 citrated peripheral blood specimens in each group of rats by dextran sedimentation and sodium metrizoate/Ficoll (lymphoprep; Nyegaard) separation (Kharazmi et al., 1984a). The remaining erythrocytes were removed by hypotonic lysis. PMNs were then counted and the concentration was adjusted to $10^{7}$ cells $\mathrm{ml}^{-1}$ in Krebs Ringer's solution with $5 \mathrm{mM}$ glucose. The purity and cell viability were both $>97 \%$.

Blood PMN chemiluminescence. A luminol-enhanced assay was performed with a luminometer (model 1251; LKBWallac), which was placed in an air-conditioned thermostatcontrolled environment at $21 \pm 1{ }^{\circ} \mathrm{C}$. Zymosan and luminol (5-amino-2,3-dihydro-1,4-phthalazinedione) were purchased from Sigma. A total volume of $1 \mathrm{ml}$ of a mixture containing $0 \cdot 1 \mathrm{ml}$ PMN suspension, $0 \cdot 2 \mathrm{ml}$ serum-opsonized zymosan at $10 \mathrm{mg} \mathrm{ml}^{-1}$ and $0.7 \mathrm{ml}$ luminol at $10^{-4} \mathrm{~mol} \mathrm{l}^{-1}$ was used. The peak chemiluminescence (in $\mathrm{mV}$ ) and the time taken to peak were measured.

Lung bacteriology. Ten to eleven random lung samples from each group of rats at each time point were prepared for quantitative bacteriological examination as described by Johansen et al. (1993). Each lung was mixed with $3 \mathrm{ml}$ cold sterile PBS and the mixture was homogenized in a blender. Appropriately diluted samples were plated on 'Blue agar plates' (a modified Conradi-Drigalsky medium selective for Gram-negative rods and containing lactose, $\mathrm{pH} 7 \cdot 0$; State Serum Institute, Copenhagen) to determine the number of bacterial c.f.u. after $20-24 \mathrm{~h}$ incubation at $37^{\circ} \mathrm{C}$.

ELISA. Serum antibody responses. The concentrations of serum $\operatorname{Ig}$ M, IgA, IgG, IgG1 and IgG2a against $P$. aeruginosa standard antigen (St-Ag) in 15 serum samples from each group of rats at each time point were determined by ELISA as reported previously (Johansen \& Høiby, 1992; Johansen et al., 1993). The serum antibody titres expressed as ELISA units were obtained by dividing the mean absorbance of the samples by the mean absorbance of an internal standard expressing between 0.30 and 0.40 absorbance units.

Cytokine production The concentrations of IL-4 and IFN- $\gamma$ in 10-11 supernatants of the lung homogenate (from the detection of lung bacteriology) from each group of rats at each time point were determined by ELISA kits (Nordic BioSite $\mathrm{AB})$. Standard curves for IL-4, ranging from 8 to $500 \mathrm{pg} \mathrm{ml}^{-1}$ (lower detection limit $2 \mathrm{pg} \mathrm{ml}^{-1}$ ), and IFN- $\gamma$, ranging from 10 to $2000 \mathrm{pg} \mathrm{ml}^{-1}$ (lower detection limit $10 \mathrm{pg} \mathrm{ml}^{-1}$ ), were constructed.

Statistical analyses. The categorical data were analysed by the chi-squared test. The Mann-Whitney U test was used to compare the data between two groups.

\section{RESULTS \\ Mortality}

Mortality of the infected rats was followed in both groups from 1 to $28 \mathrm{~d}$ post-infection (p.i.). Dead animals were mostly found on days 2 and 3 p.i. In the group of PAO1-infected rats, the mortality was $7 \cdot 5 \%(6 / 80)$, while in the lasI rblI group, it was $16.7 \%(15 / 90)$. The difference in mortality between the two groups was not statistically significant.

\section{Macroscopic lung pathology}

To calculate the LIMP, which was used as an indicator of the severity of the lung pathology, we measured the area of the lungs exhibiting pathological changes. The major pathological changes observed were lung consolidation, abscesses, adhesion, haemorrhage and atelectasis. On days 3 and 7 p.i., lung adhesion was rarely found, while lung consolidation with haemorrhage and abscesses were the main pathological changes. However, from day 14 p.i., lung adhesion and single huge or multiple lung abscesses became the important charac- 


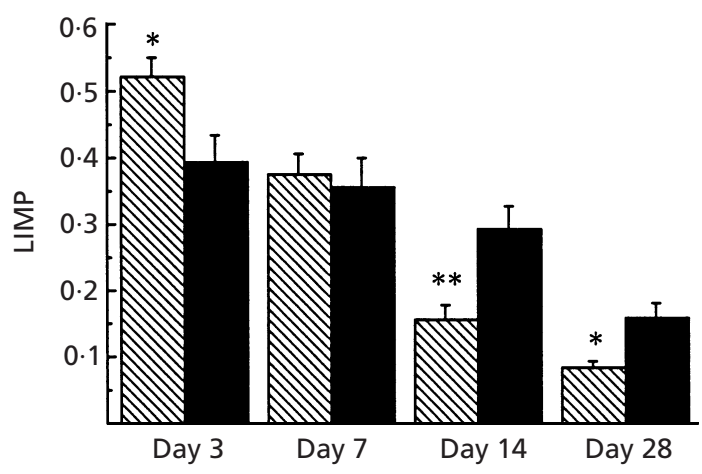

Fig. 1. Comparison of the LIMP of the PAO1 and the lasl rhll groups on different days p.i. A sharply reduced LIMP value with respect to time is observed in the lasl rhll group compared with the PAO1 group. The results are represented as the means \pm standard errors. Significant differences between groups are indicated by asterisks: ${ }^{*} P<0.01 ;{ }^{*} P<0.005$. Black bars, PAO1; hatched bars lasl rhll.

teristics, particularly in the PAO1 group. A few lung samples with atelectasis were found on day 28 p.i. in both groups of rats. The LIMP in the lasI rbll group was higher $(P<0.007)$ on day 3 p.i. but declined significantly on days 14 and 28 p.i. $(P<0.003$ and $P<0.008$, respectively) compared to the PAO1 group. On day 7 p.i., no difference was observed between the two groups (Fig. 1). In the las I rhll group, each of the differences in the LIMP between days 3 and 7 p.i. $(P<$ $0.04)$, days 7 and 14 p.i. $(P<0.001)$, and days 14 and 28 p.i. $(P<0.02)$ was significant. In contrast, each of the differences in the LIMP between days 3 and 7 p.i. and days 7 and 14 p.i. in the PAO1 group was not significant; only the difference between days 14 and 28 p.i. was significant $(P<0.005)$. These results indicated that PAO1 caused more persistent and severe lung pathological changes than PAO1 lasI rbli.

\section{Lung histopathology}

To classify the lung inflammation and the severity of lung damage, we measured the diameters of lung

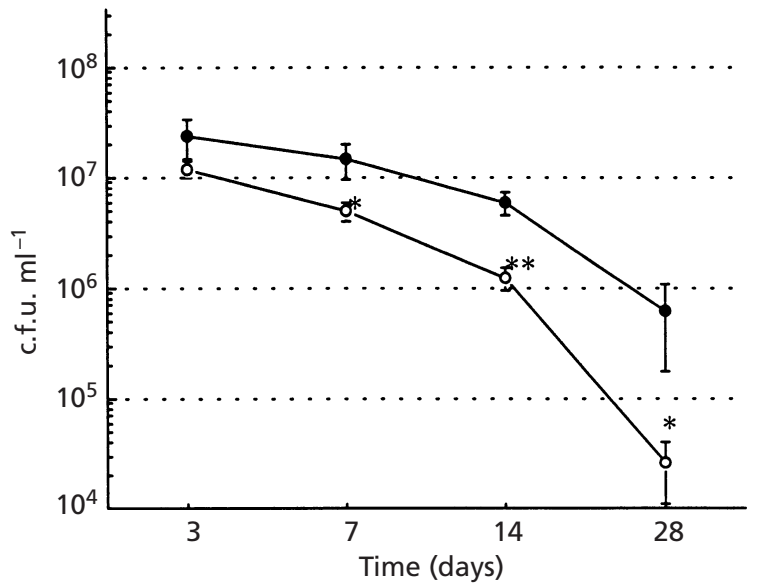

Fig. 2. Number of lung bacteria in the PAO1 and the lasl rhll groups. The bacterial number decreases more quickly in the lasl rhll group than the PAO1 group. The results are expressed as the means \pm standard errors of the c.f.u. $\mathrm{ml}^{-1}$. Significant differences between groups are indicated by asterisks: ${ }^{*} P<$ $0.05 ; * * P<0.01$., PAO 1; O, lasl rhll.

abscesses, determined the proportions of PMNs and MNs, and counted the number of mast cells in lung foci. Acute lung inflammation with significant infiltration of PMNs, single huge or multiple lung abscesses with significant tissue damage, oedema, haemorrhage and consolidation were seen in both groups of rats from days 3 to 14 p.i. Chronic lung inflammation could be seen in only three out of eight lungs from both groups on day 28 p.i. There was no difference in the inflammatory classification between the two groups on days 3, 7, 14 and 28 p.i. However from days 14 to 28 p.i., the size of lung abscesses in the lasI rhll group was reduced compared to the PAO1 group $(P<0.05)$ (Table 2$)$. On day 7 p.i. similarly sized lung abscesses were found in the two groups. On day 3 p.i. we were unable to determine the size of the lung abscesses because the border of the abscess was not well defined. Mast cells were found along the lung foci. Significant degranulation was observed in the mast cells closer to the centre of an inflammatory focus. The mast cell count in the lasI rhlI

Table 2. Size of lung abscesses and number of lung mast cells

Values are expressed as the median with the range in parentheses. Ns, Not significant.

\begin{tabular}{|c|c|c|c|c|c|}
\hline \multirow[t]{2}{*}{ Group } & \multicolumn{3}{|c|}{ Diameter of abscess (mm) } & \multicolumn{2}{|c|}{ No. mast cells* } \\
\hline & Day 7 & Day 14 & Day $28 \dagger$ & Day 14 & Day 28 \\
\hline PAO1 & $5 \cdot 8(2 \cdot 8-15 \cdot 2)$ & $12 \cdot 4(5 \cdot 8-18 \cdot 8)$ & $10 \cdot 0(1 \cdot 6-16 \cdot 4)$ & $76(15-140)$ & $133(46-215)$ \\
\hline lasI rhlI & $11 \cdot 2(6 \cdot 8-16 \cdot 4)$ & $8 \cdot 2(0 \cdot 0-14 \cdot 4)$ & $5 \cdot 0(0 \cdot 5-8 \cdot 0)$ & $45(36-97)$ & $46(7-94)$ \\
\hline PAO1 vs. lasI rhlI & NS & $P<0.04$ & $P<0.05$ & NS & $P<0.03$ \\
\hline
\end{tabular}

* The mast cells were counted in 10 microscopic fields (magnification, $400 \times$ ) along the inflammatory area.

† Five animals were used in each group; abscesses were only seen in 5 of 8 rats in each group. 
Table 3. Peripheral blood PMN chemiluminescence on different days p.i.

The results are expressed as the median with the range given in parentheses. The unit is $\mathrm{mV}$. Ns, Not significant.

\begin{tabular}{|cccc|}
\hline $\begin{array}{l}\text { Days } \\
\text { p.i. }\end{array}$ & \multicolumn{2}{c}{ Group } & $\begin{array}{c}\text { PAO1 vs. lasI } \\
\text { rhlI }\end{array}$ \\
\cline { 2 - 4 } & PAO1 & lasI rhlI & \\
\hline 3 & $6 \cdot 51(2 \cdot 81-14 \cdot 95)$ & $9 \cdot 75(4 \cdot 91-19 \cdot 45)$ & $P<0.05$ \\
7 & $28 \cdot 12(17.95-33 \cdot 85)$ & $32.57(15 \cdot 10-48 \cdot 12)$ & NS \\
14 & $4.65(3.57-9 \cdot 97)$ & $4 \cdot 50(2 \cdot 85-9 \cdot 50)$ & NS \\
\hline
\end{tabular}

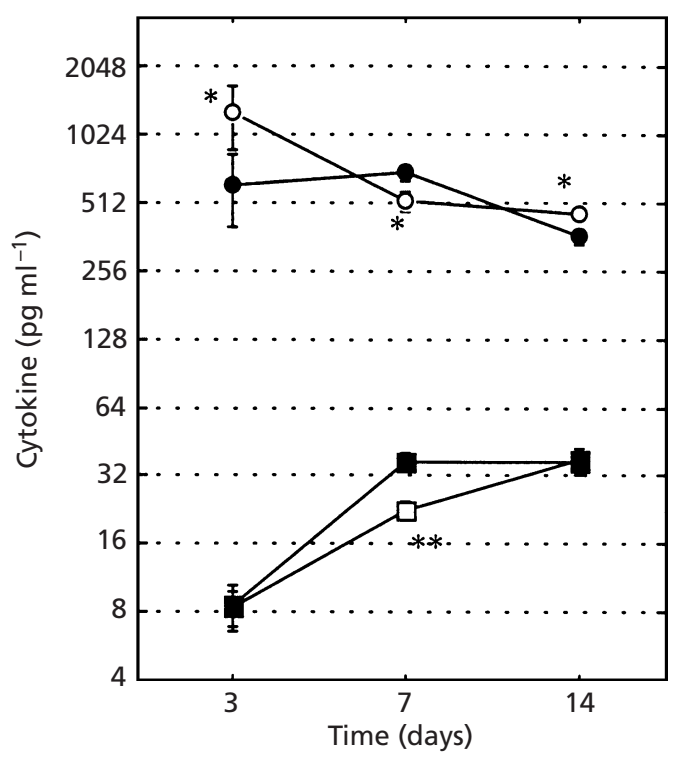

Fig. 3. Amount of cytokines in lung tissues on different days p.i. in the PAO1 and lasl rhll groups. A higher level of IFN- $\gamma$ on days 3 and 14 p.i. was found in the lasl rhll group, but both higher IFN- $\gamma$ and IL-4 levels on day 7 were detected in the PAO1 group. Values are expressed as the mean \pm standard errors of the $\mathrm{pg} \mathrm{ml}^{-1}$. Significant differences between groups are indicated by asterisks: ${ }^{*} P<0.05 ; * * P<0.01$. P, PAO1 IFN $-\gamma$; ○, lasl rhll IFN- $\gamma ; \boldsymbol{\square}$, PAO1 IL-4; $\square$, lasl rhll IL-4.

group was notably lower than in the PAO1 group on day 28 p.i. $(P<0 \cdot 03)$ (Table 2$)$.

\section{Lung bacteriology}

Bacteria from the lung tissues of both groups of rats were enumerated and the results enabled us to evaluate the ability of PAO1 and PAO1 lasI rblI to resist host immune clearance. On day 3 p.i., the bacterial counts from both groups of rats did not differ significantly. The bacterial counts in the lasI rhlI group dropped significantly on days 7,14 and 28 p.i. $(P<0 \cdot 05, P<0 \cdot 01$ and $P<0 \cdot 04$, respectively, Fig. 2) compared to the PAO1 group. In the lasI rhlI group, the lung bacteriology decreased progressively with time, i.e. the number of

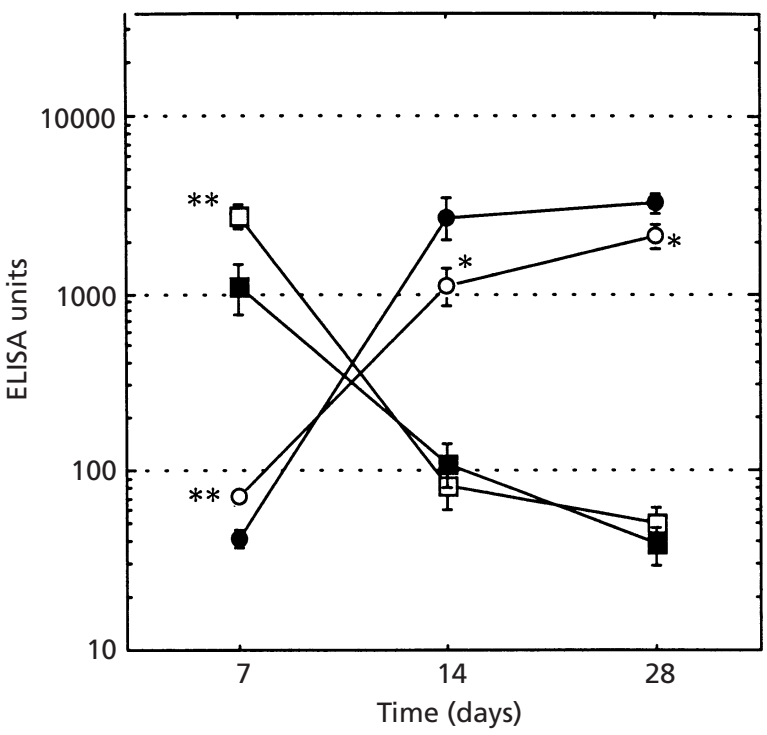

Fig. 4. Serum antibody responses against St-Ags on different days p.i. in the PAO1 and lasl rhll groups. Stronger IgM and IgG responses on day 7 but weaker IgG production on days 14 and 28 are seen in the lasl rhll group, compared with the PAO1 group. The levels of antibodies are expressed as the means \pm standard errors of ELISA units. Significant differences between groups are indicated by asterisks: ${ }^{*} P<0.05$; ${ }^{* *} P<$ 0.01. O, lasl rhll lgG; $\square$, lasl rhll lgM; ○, PAO1 lgG;, PAO1 $\lg \mathrm{M}$.

bacteria in the lungs on day 3 p.i. was higher than that on day 7 p.i. $(P<0 \cdot 006)$, day 7 p.i. was higher than day 14 p.i. $(P<0 \cdot 006)$ and day 14 p.i. was higher than day 28 p.i. $(P<0 \cdot 0005)$. The lung bacteriology in the lasI rhll group correlated positively with the LIMP $(P<$ $0 \cdot 025, r=0 \cdot 976)$. In contrast, there was no significant difference between the numbers of bacteria in the lungs on days 3 and 7 p.i., and days 7 and 14 p.i. in the PAO1 group, except on day 28 p.i., which was significantly lower than that on day 14 p.i. $(P<0 \cdot 001)$. These results suggested that the signal-generation-defective bacteria were cleared away more quickly than the wild-type $P$. aeruginosa PAO1.

\section{Blood PMN chemiluminescence}

Myeloperoxidase-mediated chemiluminescence is one of the major antimicrobial systems manifested by PMNs (Kharazmi et al., 1984a). The results showed that the PMN chemiluminescence response in the lasI rbll group was higher on day 3 p.i. than that in the corresponding PAO1 group $(P<0 \cdot 05)$. No difference in the PMN chemiluminescence response was found between the two groups of rats on days 7 and 14 p.i. (Table 3). The PMN chemiluminescence on day 7 p.i. in both groups of rats was significantly higher compared with that on day 3 p.i. $(P<0.0002)$. On day 14 p.i., the PMN chemiluminescence in both groups decreased markedly compared to day 7 p.i. (Table 3 ). 


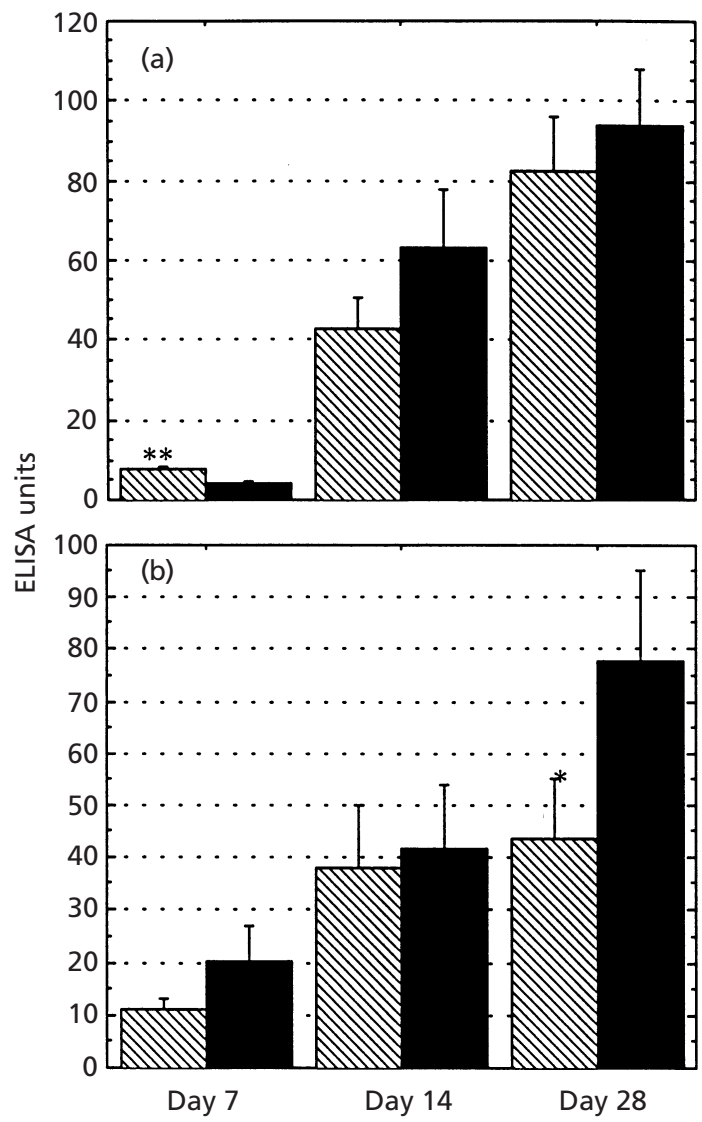

Fig. 5. Serum IgG subclasses response against St-Ags on different days after challenge in the PAO1 and lasl rhll groups. The results are expressed as the means \pm standard errors of ELISA units. (a) Higher IgG2a production on day 7 is seen in the lasl rhll group. Hatched bars, lasl rhll Ig2a; black bars, PAO1 Ig2a. (b) Significantly increased IgG1 level on day 28 is found in the PAO1 group. Hatched bars, lasl rhll, IgG1; black bars, PAO1 IgG1. Significant differences between groups are indicated by asterisks: ${ }^{*} P<0.05 ; * * P<0.0005$.

\section{Cytokine production from the lungs}

The type of immune response depends on the profile of cytokines. On day 3 p.i., severe lung pathological changes occurred in both groups of rats. The amount of the lung IFN- $\gamma$ in the lasI rhlI group was significantly higher than that in the PAO1 group $(P<0 \cdot 02)$. On day 14 p.i., a higher IFN- $\gamma$ level could still be detected in the lasI rbll group $(P<0.05)$. The production of IL-4 and IFN $-\gamma$ in the PAO1 group were higher than those in the lasI rhll group on day 7 p.i. $(P<0.03)$ (Fig. 3), indicating a delay in the immune response in rats infected by PAO1.

\section{Serum antibody responses}

On days 7, 14 and 28 p.i., the serum antibody levels against $P$. aeruginosa $\mathrm{St}-\mathrm{Ag}$ and alginate were measured by ELISA.
Anti-P. aeruginosa St-Ag antibody responses. During the early immune response, serum IgM and IgG levels in the lasI rhlI group were significantly higher than those in the PAO1 group $(P<0 \cdot 007)$. However, from day 14 p.i., the situation changed. The IgG titre found in the lasI rhl group was much lower than that in the PAO1 group ( $P$ $<0.05)$, and the $\operatorname{IgM}$ response in both groups dropped markedly (Fig. 4). The production of IgA in the two groups of rats did not differ significantly (data not shown).

Anti-P. aeruginosa St-Ag IgG subclass response. In the lasI rhll group, the IgG2a level was notably higher on day 7 p.i. $(P<0.0004)$ and the IgG1 level was lower on day 28 p.i. when compared with the levels in the corresponding PAO1 group $(P<0 \cdot 05)$. On day 14 p.i., the response of $\operatorname{IgG} 2 \mathrm{a}$ did not differ between the two groups of rats. However, in both groups the IgG2a titres on days 14 and 28 p.i. were much higher than the $\operatorname{IgG} 2 \mathrm{a}$ titre on day 7 p.i., and the increase in IgG2a paralleled that in IgG. The IgG1 response was similar in the two groups of rats on days 7 and 14 p.i. (Fig. 5).

\section{DISCUSSION}

Our results revealed that infection with $P$. aeruginosa lasI rhll, a strain with defective quorum sensing signalgenerating systems, resulted in a faster and stronger immune response against the bacterial infection in the early phase as judged from the severity of lung pathology (Fig. 1), higher lung IFN- $\gamma$ production (Fig. 3), stronger oxidative burst of blood PMNs (Table 3) and faster antibody response (Figs 4 and 5), compared to the infection with wild-type $P$. aeruginosa PAO1. Subsequently, quicker bacterial clearance from the lungs (Fig. 2), milder lung pathology (Fig. 1 and Table 2) and a more pronounced early humoral immune response (Fig. 4 and 5) were also detected in the rats infected with PAO1 lasI rblI in comparison with the PAO1-infected rats.

A stronger oxidative burst response in peripheral blood PMNs is indirect evidence of PMN activation in the lung. During the initial infection process host phagocytes commonly play a major role in the defence against invading micro-organisms. Among the phagocytes, blood PMNs are the most active and important. Previous studies have shown that some $P$. aeruginosa virulence factors, such as alkaline protease and elastase, could interfere with phagocytosis of neutrophils (Kharazmi et al., 1984a, b, 1986), especially inhibiting the oxidative burst response of neutrophils to opsonized zymosan. Our results suggest that PAO1 lasI rhlI produces less virulence factors and lessens the suppression of the PMN oxidative burst in early stages of lung infection, which would be helpful for the lung phagocytes to kill the bacteria. On the other hand, wild-type $P$. aeruginosa PAO1 can be induced to produce extracellular products which inhibit PMN chemiluminescence (Table 3), one of the major antimicrobial systems of PMNs. The increased chemiluminescence is required for the bactericidal activity of PMNs but it might also, in some 
circumstances, worsen the tissue damage (Kharazmi et al., 1989) (Fig. 1). The release of elastase and other lysosomal enzymes from neutrophils are other likely candidates participating in the process of tissue damage (Doring \& Dauner, 1988; Doring, 1994). IFN- $\gamma$ is known to enhance the oxidative burst of PMNs in response to lipopolysaccharide, to increase neutrophil-mediated antibody-dependent cytotoxicity, and to facilitate phagocytosis and bactericidal activity by increasing the expression of high affinity $\operatorname{IgG}$ receptors and $\mathrm{C} 3 \mathrm{~b}$ receptors on PMNs (Hokland \& Berg, 1981; Petroni et al., 1988; Roilides et al., 1992). The results of lung bacteriology showed that the lung bacterial clearance in the las I rhll group was significantly faster than that in the PAO1 group, suggesting that it may be associated with an early stronger PMN chemiluminescence response in the lasI rhlI group. On day 7 p.i., PMN chemiluminescence in both groups increased markedly compared with that found on day 3 p.i., suggesting the suppression of PMN activity on day 3 p.i., which might be associated with the septicaemia found at the same time (Solberg et al., 1982). Spleen culture showed that $P$. aeruginosa could be detected in $60-70 \%$ of the rats in both groups on day 3 p.i., indicating septicaemia. On day 7 p.i., the pathogen was no longer found in the spleen (data not shown). However, the difference of PMN chemiluminescence between the two groups was not significant on days 7 and 14 p.i. This might be due to the formation of serum $\operatorname{IgM}$ directed against virulence factors in the PAO1 group, thereby removing the inhibition of PMN chemiluminescence by virulence factors.

On day 7 p.i., higher lung IFN- $\gamma$ and IL-4 production as well as lower serum $\operatorname{IgM}, \operatorname{IgG}$ and $\operatorname{IgG} 2$ a responses were detected in the PAO1 group than the lasI rblI group. This may reflect a delayed immune response due to the cleaving effects on immunoglobulins by the virulence factors produced by wild-type PAO1 (Doring et al., 1981, 1984; Bainbridge \& Fick, 1989) (Figs 3, 4 and 5). The lower lung IFN- $\gamma$ on day 3 p.i. may be partly due to the inactivation of IFN $-\gamma$ by the alkaline protease and elastase of PAO1 (Horvat et al., 1989). The higher production of lung IFN $-\gamma$ on day 7 p.i. in the PAO1 group could be explained by the formation of neutralizing antibody (IgM) in the serum. Cytokines are released from macrophages, lymphocytes and appropriately stimulated cells during the infection. In lung foci produced by $P$. aeruginosa infection, the accumulation of different cytokines would lead to local induction of the Th cell response towards the Th1/Th2 type. Highlevel production of IFN- $\gamma$ activates macrophages and facilitates the production of the IgG2a subclass, which correlates with the Th1 response. The Th1 response favours cell-mediated immunity (Mosmann \& Coffman, 1989; Mosmann \& Sad, 1996). High-level production of IL-4 would stimulate the humoral immunity and promote the production of the IgG1 subclass, which associates with the Th2 response (Haczku et al., 1996; Mosmann \& Sad, 1996). The Th1 response would benefit the host fighting against chronic $P$. aeruginosa lung infection and the Th2 response correlates with a poor prognosis (Johansen et al., 1996; Moser et al., 1997; Song et al., 1997). Telford et al. (1998) suggested on the basis of an in vitro study that $\mathrm{N}$-oxododecanoyl homoserine lactone, a major signal molecule produced by LasI, inhibits the production of IL-12, a Th1supportive cytokine, and induces a Th2-like response (increases IgG1 level and stimulates the production of $\operatorname{IgE}$ with IL-4). Our results provide in vivo evidence regarding production of cytokines during $P$. aeruginosa lung infection and supports the view that AHLs originating from the quorum sensing systems of $P$. aeruginosa are important in the pathogenesis of chronic pulmonary infection.

From days 14 to 28 p.i., milder pathology, lower mast cell count, higher IFN- $\gamma$ production in lungs, and lower serum IgG and $\operatorname{IgG} 1$ responses were found in the PAO1 lasI rhll infected group when compared with the PAO1 infected group, indicating a Th1-like immune response. Mast cells and serum IgG and IgG1 are involved in Th2 responses (Johansen et al., 1996; Krishnan et al., 1996; Mosmann \& Sad, 1996; Moser et al., 1997). Chronic $P$. aeruginosa lung infection in CF patients is characterized by the persistent and significant antibody response in serum and the remarkable infiltration of PMNs in the lung (Høiby et al., 1990). In the present study, a higher serum IgG level was found in the PAO1 infected rats than the PAO1 lasI rhll infected rats during the chronic lung infection. The increased level of serum antibodies could lead to the formation of a larger quantity of immune complexes in the lung foci and this is thought to play an important role in the immunopathology of CF. In addition, the larger number of mast cells in the lung foci leading to the release of PMN chemoattractants, together with the activation of complement by the immune complexes would result in significant infiltration of PMNs into the lung foci and damage of the lung tissues (Abraham \& Malaviya, 1996). Moreover, a high antibody titre in CF patients with chronic $P$. aeruginosa lung infection has been correlated with a poor prognosis (Høiby et al., 1986, 1990). The results of antibody responses revealed that $P$. aeruginosa PAO1 with the ability of producing AHLs inhibited the immune response during the early phase of infection but stimulated the humoral immune reaction during the chronic infection.

Our results suggest that functional quorum sensing systems significantly affect the severity of $P$. aeruginosa lung infection in both acute and chronic phases. AHL signal molecules as well as receptors (LasR and RhlR) are therefore promising new targets in the quest for a new type of therapy of CF patients with chronic $P$. aeruginosa lung infection.

\section{ACKNOWLEDGEMENTS}

We thank Barbara H. Iglewski's group, Department of Microbiology and Immunology, University of Rochester, USA, for providing $P$. aeruginosa PAO1 wild-type and PAO1 lasI rhlI. We also thank Jette Pedersen for her assiduity during 
the histopathological examination. We are grateful for the English checking given kindly by Professor Chong-Lek Koh, $\mathrm{PhD}$, University of Malaya, Malaysia. This work was supported by grants from the Danish Medical Research to M.G.

\section{REFERENCES}

Abraham, S. N. \& Malaviya, R. (1996). Role of mast cells in bacterial clearance in the lung. Mucosal Immunology Update 4, 58-60.

Bainbridge, T. \& Fick, R. B., Jr (1989). Functional importance of cystic fibrosis immunoglobulin $G$ fragments generated by Pseudomonas aeruginosa elastase. J Lab Clin Med 114, 728-733.

Brint, J. M. \& Ohman, D. E. (1995). Synthesis of multiple exoproducts in Pseudomonas aeruginosa is under the control of RhlR-RhlI, another set of regulators in strain PAO1 with homology to the autoinducer-responsive LuxR-LuxI family. $J$ Bacteriol 177, 7155-7163.

Chapon-Herve, V., Akrim, M., Latifi, A., Williams, P., Lazdunski, A. \& Bally, M. (1997). Regulation of the xcp secretion pathway by multiple quorum-sensing modulons in Pseudomonas aeruginosa. Mol Microbiol 24, 1169-1178.

Ciofu, O., Giwercman, B., Pedersen, S. S. \& Høiby, N. (1994). Development of antibiotic resistance in Pseudomonas aeruginosa during two decades of antipseudomonal treatment at the Danish CF Center. APMIS 102, 674-680.

Doring, G. (1994). The role of neutrophil elastase in chronic inflammation. Am J Respir Crit Care Med 150, S114-S117.

Doring, G. \& Dauner, H. M. (1988). Clearance of Pseudomonas aeruginosa in different rat lung models. Am Rev Respir Dis 138, 1249-1253.

Doring, G., Obernesser, H. J. \& Botzenhart, K. (1981). Extracellular toxins of Psendomonas aeruginosa. II. Effect of two proteases on human immunoglobulins $\operatorname{IgG}, \operatorname{IgA}$ and secretory IgA. Zentbl Bakteriol A 249, 89-98.

Doring, G., Dalhoff, A., Vogel, O., Brunner, H., Droge, U. \& Botzenhart, K. (1984). In vivo activity of proteases of Pseudomonas aeruginosa in a rat model. J Infect Dis 149, 532-537.

Doring, G., Goldstein, W., Roll, A., Schiotz, P. O., Høiby, N. \& Botzenhart, K. (1985). Role of Pseudomonas aeruginosa exoenzymes in lung infections of patients with cystic fibrosis. Infect Immun 49, 557-562.

Doring, G., Maier, M., Muller, E., Bibi, Z., Tummler, B. \& Kharazmi, A. (1987). Virulence factors of Pseudomonas aeruginosa. Antibiot Chemother 39, 136-148.

Finch, R. G., Pritchard, D. I., Bycroft, B. W., Williams, P. \& Stewart, G. S. (1998). Quorum sensing: a novel target for anti-infective therapy. J Antimicrob Chemother 42, 569-571.

Fuqua, C. \& Greenberg, E. P. (1998). Self perception in bacteria: quorum sensing with acylated homoserine lactones. Curr Opin Microbiol 1, 183-189.

Fuqua, C., Winans, S. C. \& Greenberg, E. P. (1996). Census and consensus in bacterial ecosystems: the LuxR-LuxI family of quorum-sensing transcriptional regulators. Annu Rev Microbiol 50, 727-751.

Gambello, M. J. \& Iglewski, B. H. (1991). Cloning and characterization of the Pseudomonas aeruginosa lasR gene, a transcriptional activator of elastase expression. J Bacteriol 173, 3000-3009.

Gambello, M. J., Kaye, S. \& Iglewski, B. H. (1993). LasR of Pseudomonas aeruginosa is a transcriptional activator of the alkaline protease gene $(a p r)$ and an enhancer of exotoxin A expression. Infect Immun 61, 1180-1184.

Glessner, A., Smith, R., Iglewski, B. \& Robinson, J. (1999). Roles of Pseudomonas aeruginosa las and $r h l$ quorum-sensing systems in control of twitching motility. J Bacteriol 181, 1623-1629.

Govan, J. R. \& Deretic, V. (1996). Microbial pathogenesis in cystic fibrosis: mucoid Pseudomonas aeruginosa and Burkholderia cepacia. Microbiol Rev 60, 539-574.

Haczku, A., Macary, P., Haddad, E. B., Huang, T. J., Kemeny, D. M., Moqbel, R. \& Chung, K. F. (1996). Expression of Th-2 cytokines interleukin-4 and -5 and of Th-1 cytokine interferongamma in ovalbumin-exposed sensitized Brown-Norway rats. Immunology 88, 247-251.

Hartman, G. \& Wise, R. (1998). Quorum sensing: potential means of treating gram-negative infections? Lancet 351, 848-849.

Høiby, N. (1993). Cystic fibrosis and endobronchial Pseudomonas infection. Curr Opin Pediatr 5, 247-254.

Høiby, N., Doring, G. \& Schiotz, P. O. (1986). The role of immune complexes in the pathogenesis of bacterial infections. Annu Rev Microbiol 40, 29-53.

Høiby, N., Pedersen, S. S., Jensen, E. T., Pressler, T., Shand, G. H., Kharazmi, A. \& Doring, G. (1990). Immunology of Pseudomonas aeruginosa infection in cystic fibrosis. Acta Univ Carol Med Praha 36, 16-21.

Hokland, P. \& Berg, K. (1981). Interferon enhances the antibodydependent cellular cytotoxicity (ADCC) of human polymorphonuclear leukocytes. J Immunol 127, 1585-1588.

Horvat, R. T., Clabaugh, M., Duval, J. C. \& Parmely, M. J. (1989). Inactivation of human gamma interferon by Pseudomonas aeruginosa proteases: elastase augments the effects of alkaline protease despite the presence of alpha 2-macroglobulin. Infect Immun 57, 1668-1674.

Jaeger, K. E. (1994). Extracellular enzymes of Pseudomonas aeruginosa as virulence factors. Immun Infekt 22, 177-180.

Johansen, H. K. \& Høiby, N. (1992). Local $\operatorname{IgA}$ and $\operatorname{IgG}$ response to intratracheal immunization with Pseudomonas aeruginosa antigens. APMIS 100, 87-90.

Johansen, H. K., Espersen, F., Pedersen, S. S., Hougen, H. P., Rygaard, J. \& Høiby, N. (1993). Chronic Pseudomonas aeruginosa lung infection in normal and athymic rats. APMIS 101, 207-225.

Johansen, H. K., Espersen, F., Cryz, S. J., Hougen, H. P., Fomsgaard, A., Rygaard, J. \& Høiby, N. (1994). Immunization with Pseudomonas aeruginosa vaccines and adjuvant can modulate the type of inflammatory response subsequent to infection. Infect Immun 62, 3146-3155.

Johansen, H. K., Hougen, H. P., Rygaard, J. \& Høiby, N. (1996). Interferon-gamma (IFN-gamma) treatment decreases the inflammatory response in chronic Pseudomonas aeruginosa pneumonia in rats. Clin Exp Immunol 103, 212-218.

Kharazmi, A., Høiby, N., Doring, G. \& Valerius, N. H. (1984a). Pseudomonas aeruginosa exoproteases inhibit human neutrophil chemiluminescence. Infect Immun 44, 587-591.

Kharazmi, A., Doring, G., Høiby, N. \& Valerius, N. H. (1984b). Interaction of Pseudomonas aeruginosa alkaline protease and elastase with human polymorphonuclear leukocytes in vitro. Infect Immun 43, 161-165.

Kharazmi, A., Eriksen, H. O., Doring, G., Goldstein, W. \& Høiby, N. (1986). Effect of Pseudomonas aeruginosa proteases on human leukocyte phagocytosis and bactericidal activity. Acta Pathol Microbiol Immunol Scand C 94, 175-179. 
Kharazmi, A., Bibi, Z., Nielsen, H., Høiby, N. \& Doring, G. (1989). Effect of Pseudomonas aeruginosa rhamnolipid on human neutrophil and monocyte function. APMIS 97, 1068-1072.

Kiernan, J. A. (editor) (1981). Histological and Histochemical Methods: Theory and Practice. Oxford: Pergamon Press.

Krishnan, L., Guilbert, L. J., Russell, A. S., Wegmann, T. G., Mosmann, T. R. \& Belosevic, M. (1996). Pregnancy impairs resistance of C57BL/6 mice to Leishmania major infection and causes decreased antigen-specific IFN-gamma response and increased production of $\mathrm{T}$ helper 2 cytokines. J Immunol 156, 644-652.

Latifi, A., Foglino, M., Tanaka, K., Williams, P. \& Lazdunski, A. (1996). A hierarchical quorum-sensing cascade in Pseudomonas aeruginosa links the transcriptional activators LasR and RhIR (VsmR) to expression of the stationary-phase sigma factor RpoS. Mol Microbiol 21, 1137-1146.

May, T. B., Shinabarger, D., Maharaj, R. \& 7 other authors (1991). Alginate synthesis by Pseudomonas aeruginosa: a key pathogenic factor in chronic pulmonary infections of cystic fibrosis patients. Clin Microbiol Rev 4, 191-206.

Moser, C., Johansen, H. K., Song, Z., Hougen, H. P., Rygaard, J. \& Høiby, N. (1997). Chronic Pseudomonas aeruginosa lung infection is more severe in Th2 responding BALB/c mice compared to Th1 responding $\mathrm{C} 3 \mathrm{H} / \mathrm{HeN}$ mice. APMIS 105, 838-842.

Mosmann, T. R. \& Coffman, R. L. (1989). TH1 and TH2 cells: different patterns of lymphokine secretion lead to different functional properties. Annu Rev Immunol 7, 145-173.

Mosmann, T. R. \& Sad, S. (1996). The expanding universe of T-cell subsets: Th1, Th2 and more. Immunol Today 17, 138-146.

Ochsner, U. A. \& Reiser, J. (1995). Autoinducer-mediated regulation of rhamnolipid biosurfactant synthesis in Pseudomonas aeruginosa. Proc Natl Acad Sci U S A 92, 6424-6428.

Passador, L., Cook, J. M., Gambello, M. J., Rust, L. \& Iglewski, B. H. (1993). Expression of Pseudomonas aeruginosa virulence genes requires cell-to-cell communication. Science 260, $1127-1130$.

Pearson, J. P., Gray, K. M., Passador, L., Tucker, K. D., Eberhard, A., Iglewski, B. H. \& Greenberg, E. P. (1994). Structure of the autoinducer required for the expression of Pseudomonas aeruginosa virulence genes. Proc Natl Acad Sci U S A 91, 197-201.

Pearson, J. P., Passador, L., Iglewski, B. H. \& Greenberg, E. P. (1995). A second $N$-acylhomoserine lactone signal produced by Pseudomonas aeruginosa. Proc Natl Acad Sci USA 92, 1490-1494.

Pearson, J., Pesci, E. \& Iglewski, B. (1997). Roles of Pseudomonas aeruginosa las and $r h l$ quorum-sensing systems in control of elastase and rhamnolipid biosynthesis genes. J Bacteriol 179, 5756-5767.

Pedersen, S. S. (1992). Lung infection with alginate-producing, mucoid Pseudomonas aeruginosa in cystic fibrosis. APMIS Suppl 28, 1-79.

Pedersen, S. S., Shand, G. H., Hansen, B. L. \& Hansen, G. N. (1990). Induction of experimental chronic Pseudomonas aeruginosa lung infection with $P$. aeruginosa entrapped in alginate microspheres. APMIS 98, 203-211.

Pesci, E. C. \& Iglewski, B. H. (1997). The chain of command in Pseudomonas quorum sensing. Trends Microbiol 5, 132-135.

Pesci, E. C., Pearson, J. P., Seed, P. C. \& Iglewski, B. H. (1997). Regulation of las and $r h l$ quorum sensing in Pseudomonas aeruginosa. J Bacteriol 179, 3127-3132.
Petroni, K. C., Shen, L. \& Guyre, P. M. (1988). Modulation of human polymorphonuclear leukocyte $\operatorname{IgG} \mathrm{Fc}$ receptors and $\mathrm{Fc}$ receptor-mediated functions by IFN-gamma and glucocorticoids. J Immunol 140, 3467-3472.

Pollack, M. (1984). The virulence of Pseudomonas aeruginosa. Rev Infect Dis 6 Suppl 3, S617-S626.

Roilides, E., Uhlig, K., Venzon, D., Pizzo, P. A. \& Walsh, T. J. (1992). Neutrophil oxidative burst in response to blastoconidia and pseudohyphae of Candida albicans: augmentation by granulocyte colony-stimulating factor and interferon-gamma. $J$ Infect Dis 166, 668-673.

Rumbaugh, K. P., Griswold, J. A., Iglewski, B. H. \& Hamood, A. N. (1999). Contribution of quorum sensing to the virulence of Pseudomonas aeruginosa in burn wound infections. Infect Immun 67, 5854-5862.

Salmond, G. P., Bycroft, B. W., Stewart, G. S. \& Williams, P. (1995). The bacterial 'enigma': cracking the code of cell-cell communication. Mol Microbiol 16, 615-624.

Seed, P. C., Passador, L. \& Iglewski, B. H. (1995). Activation of the Pseudomonas aeruginosa lasI gene by LasR and the Pseudomonas autoinducer PAI: an autoinduction regulatory hierarchy. $J$ Bacteriol 177, 654-659.

Solberg, C. O., Kalager, T., Hill, H. R. \& Glette, J. (1982). Polymorphonuclear leukocyte function in bacterial and viral infections. Scand J Infect Dis 14, 11-18.

Song, Z., Johansen, H. K., Faber, V., Moser, C., Kharazmi, A., Rygaard, J. \& Høiby, N. (1997). Ginseng treatment reduces bacterial load and lung pathology in chronic Pseudomonas aeruginosa pneumonia in rats. Antimicrob Agents Chemother 41, 961-964.

Song, Z., Kharazmi, A., Wu, H., Faber, V., Moser, C., Krogh, H. K., Rygaard, J. \& Høiby, N. (1998). Effects of ginseng treatment on neutrophil chemiluminescence and immunoglobulin $\mathrm{G}$ subclasses in a rat model of chronic Pseudomonas aeruginosa pneumonia. Clin Diagn Lab Immunol 5, 882-887.

Tang, H. B., DiMango, D., Bryan, R., Gambello, M., Iglewski, B. H., Goldberg, J. B. \& Prince, A. (1996). Contribution of specific Pseudomonas aeruginosa virulence factors to pathogenesis of pneumonia in a neonatal mouse model of infection. Infect Immun 64, 37-43.

Telford, G., Wheeler, D., Williams, P., Tomkins, P. T., Appleby, P., Sewell, H., Stewart, G. S., Bycroft, B. W. \& Pritchard, D. I. (1998). The Pseudomonas aeruginosa quorum-sensing signal molecule $\mathrm{N}$-(3-oxododecanoyl)-L-homoserine lactone has immunomodulatory activity. Infect Immun 66, 36-42.

Van Delden, C. \& Iglewski, B. H. (1998). Cell-to-cell signaling and Pseudomonas aeruginosa infections. Emerg Infect Dis 4, 551-560.

Winson, M., Camara, M., Latifi, A. \& 10 other authors (1995). Multiple $N$-acyl-L-homoserine lactone signal molecules regulate production of virulence determinants and secondary metabolites in Pseudomonas aeruginosa. Proc Natl Acad Sci USA 92, 9427-9431.

Wu, H., Song, Z., Hentzer, M. \& 8 other authors (2000). Detection of $N$-acylhomoserine lactones in lung tissues of mice infected with Pseudomonas aeruginosa. Microbiology 146, 2481-2493.

Received 13 September 2000; revised 11 December 2000; accepted 11 January 2001. 